University of Nebraska - Lincoln

DigitalCommons@University of Nebraska - Lincoln

\title{
Are Smokers Only Using Cigarettes? Exploring Current Polytobacco Use Among an Adult Population
}

Jennifer M. Bombard

Centers for Disease Control and Prevention, Atlanta, GA, United States

Linda L. Pederson

Centers for Disease Control and Prevention, Atlanta, GA, United States

David E. Nelson

Centers for Disease Control and Prevention, Atlanta, GA, United States

Ann M. Malarcher

Centers for Disease Control and Prevention, Atlanta, GA, United States

Follow this and additional works at: https://digitalcommons.unl.edu/publichealthresources

Part of the Public Health Commons

Bombard, Jennifer M.; Pederson, Linda L.; Nelson, David E.; and Malarcher, Ann M., "Are Smokers Only Using Cigarettes? Exploring Current Polytobacco Use Among an Adult Population" (2007). Public Health Resources. 13.

https://digitalcommons.unl.edu/publichealthresources/13

This Article is brought to you for free and open access by the Public Health Resources at DigitalCommons@University of Nebraska - Lincoln. It has been accepted for inclusion in Public Health Resources by an authorized administrator of DigitalCommons@University of Nebraska - Lincoln. 


\title{
Are smokers only using cigarettes? Exploring current polytobacco use among an adult population ${ }^{2}$
}

\author{
Jennifer M. Bombard*, Linda L. Pederson, David E. Nelson, Ann M. Malarcher \\ Office on Smoking and Health, National Center for Chronic Disease and Health Promotion, \\ Centers for Disease Control and Prevention, Atlanta, GA, United States
}

\begin{abstract}
Background: The primary focus of tobacco prevention and cessation interventions has been on cigarette smoking. Polytobacco use (the concurrent use of cigarettes and one or more other tobacco product[s]), may present additional health risks and make cessation more difficult.

Methods: We determined population estimates of tobacco product use and of polytobacco use for more than 50000 adults from 10 states. Logistic regression analyses were used to determine factors independently associated with polytobacco use among men only (due to low use among women).

Results: The overall adult prevalence was $22.4 \%$ for cigarettes and $3.4 \%$ for polytobacco use. Polytobacco use was more common among men who smoked cigarettes, with $26.0 \%$ using at least one other product, compared to $4.4 \%$ of women cigarette smokers. Polytobacco use among men was significantly associated with younger age, all races/ ethnicities except Hispanic, less educational attainment, less income, and more-than-moderate alcohol use.

Conclusions: Prevention and cessation efforts need to target use of other forms of tobacco besides cigarettes, especially among younger men and men who are more-than-moderate drinkers of alcohol.

Published by Elsevier Ltd.
\end{abstract}

Keywords: Tobacco smoking; Cigarette smoking; Polytobacco use; Smokeless tobacco

\footnotetext{
The findings and conclusions in this article are those of the authors and do not necessarily represent the views of the Centers for Disease Control and Prevention.

* Corresponding author. Centers for Disease Control and Prevention, National Center for Chronic Disease Prevention and Health Promotion, Office on Smoking and Health, 4770 Buford Highway, NE Mailstop K-50, Atlanta, GA 30341, United States. Tel.: +1 770488 5728; fax: +1 7704885848 .

E-mail address: jbombard@cdc.gov (J.M. Bombard).
} 


\section{Background}

Tobacco use continues to have a substantial adverse effect on the population's health in the United States (Centers for Disease Control and Prevention [CDC], 2003, 2005a; National Cancer Institute [NCI], 1998, 1992; U.S. Department of Health and Human Services [USDHHS], 2004). Although cigarettes remain the most commonly used tobacco product, many people use other forms of tobacco regularly. It is estimated that cigars, smokeless tobacco, pipes, and bidis account for an estimated $\$ 7$ billion in consumer expenditures annually (U.S. Department of Agriculture [USDA], 2006). All of these tobacco products are associated with important health consequences (American Society of Clinical Oncology, 2003; Henley, Thun, Chao, \& Calle, 2004; NCI, 1998, 1992; Wu, Song, Ashley, \& Watson, 2004).

In general, most research studies and public health surveillance reports have focused on characteristics of users for individual tobacco products (e.g., cigarettes, smokeless tobacco) rather than on the concurrent use of two or more tobacco products, or polytobacco use. Polytobacco use is important to examine because the adverse health effects may be additive, the combined use of different tobacco products could increase the risk of tobacco-attributable disease or death relative to the use of individual products only (Wetter et al., 2002), and there is an increased risk of nicotine exposure (Gilpin \& Pierce, 2003) and possibly nicotine addiction. Individual or population-based cessation interventions may need to be modified to more effectively address the challenges and needs of polytobacco users.

A few studies have examined characteristics associated with concurrent tobacco product use among adults, specifically cigarettes and smokeless tobacco (Lando, Haddock, Klesgess, Talcott, \& Jensen, 1999; Mumford, Levy, Gitchell, \& Blackman, 2005; Wetter et al., 2002). Nationally, overall prevalence of concurrent use of cigarettes and smokeless tobacco among adults is an estimated $0.6-0.8 \%$ (Wetter et al., 2002), with prevalence much higher among men (Mumford et al., 2005; Wetter et al., 2002). Concurrent use of smokeless tobacco and cigarettes has also been found to be associated with lower educational achievement, less income, white race, living in nonmetropolitan areas, alcohol use, and highrisk behaviors among adults (Lando et al., 1999; Mumford et al., 2005; Wetter et al., 2002). Additionally, there may be differences when comparing concurrent users of cigarettes and smokeless tobacco with cigarette-only users or smokeless tobacco-only users. For example, Mumford et al. (2005) found that among men who smoked cigarettes, concurrent users were more likely to be white, to live in nonmetropolitan areas, and have lower educational attainment than men who only smoked cigarettes. At this time, no published studies were found that examined characteristics of adults who use cigarettes in combination with other tobacco products.

We defined polytobacco use as cigarette use in combination with other tobacco product use (i.e., cigar, smokeless, pipe, and/or bidi), since users of other tobacco products are likely to also use cigarettes (Delnevo, Pevzner, Hrywna, \& Lewis, 2004; Nelson, Davis, Chrismon, \& Giovino, 1996; Rigotti, Lee, \& Wechsler, 2000; Wetter et al., 2002). To our knowledge, prevalence and characteristics associated with cigarette use in combination with use of any of these tobacco products has not been examined.

We analyzed detailed tobacco use data available from 10 states from the Behavioral Risk Factor Surveillance System (BRFSS), to address two main purposes. First, we examined the prevalence of polytobacco use among adult smokers. Second, we used logistic regression modeling to identify the factors associated with polytobacco use. 


\section{Methods}

Data were obtained from the 2003 BRFSS. The BRFSS is an ongoing, state-based, random-digit-dialed telephone survey that collects self-reported behavioral and health information from a representative sample of the civilian, noninstitutionalized, U.S. population aged $\geq 18$ years. Details of this system are provided elsewhere (CDC, 2005b). Analyses were limited to the 10 states (Arkansas, Colorado, Delaware, Indiana, Nebraska, New Jersey, North Carolina, North Dakota, Texas, and Wyoming) that included an optional module of questions on tobacco products. A total of 56099 respondents in these states completed the surveys. The median CASRO (Council of American Survey Research Organization) response rate for the 10 states was 58.0\% (range: $34.4 \%-64.6 \%$ ).

To determine cigarette use status, respondents were asked about smoking 100 or more cigarettes in their lifetime (ever use), with current use defined as currently smoking cigarettes every day or some days among ever smokers (CDC, 2005c). To assess current use of cigar, smokeless tobacco, pipes, and bidis, respondents were asked a question about ever use of each product individually, with a follow-up question for ever users about current use, defined for each product as use every day or some days. Polytobacco use, as mentioned previously, was defined as being a current cigarette smoker and being a current user of one or more other tobacco products. We chose to explore polytobacco this way due to the high prevalence of cigarette use and an interest in determining what proportion of cigarette smokers were also using other tobacco products.

\section{Analyses}

Data were combined for all 10 states, and all analyses were conducted using SAS, Version 8-2 (SAS Institute Inc, Cary, NC) and SUDAAN, Version 9 (Research Triangle Institute, Research Triangle Park, NC). We calculated overall and demographic-specific estimates for the prevalence of each specific product among the whole population and for polytobacco use among current smokers. The demographic categories included gender, age (18-29, 30-44, 45+), race/ethnicity (white, black, other [which included Asians, Native Hawaiians, Other Pacific Islanders, American Indians, Alaskan Natives, or Multiracial adults], Hispanic), and household income level ( $\leq \$ 19999, \$ 20000-\$ 49999, \geq \$ 50000)$. Because previous studies suggested that heavier alcohol use was associated with use of multiple tobacco products, we also analyzed data by alcohol consumption, (i.e., "more-than-moderate use" among men and women was $>2$ drinks per day and $>1$ drink per day, respectively, and "moderate use or less" for men and women was $\leq 2$ drinks per day and $\leq 1$ drink per day, respectively [USDHHS \& USDA, 2005]). Bivariate analyses were used to identify demographic and drinking characteristics that were associated with each specific product (compared to nonuse of that specific product) and with polytobacco use among current smokers (compared to nonuse of any tobacco product).

To determine whether the demographic factors or alcohol use were still associated with polytobacco use after adjusting for other variables, we conducted multivariate modeling to calculate odds ratios. Because preliminary analyses indicated very low use of other tobacco products among women, multivariate analyses were restricted to men.

\section{Results}

\subsection{Cigarette, cigar, smokeless tobacco, pipe, and bidi use}

Among the 10 states, the overall adult prevalence for each tobacco product was $22.4 \%$ for cigarettes, $5.7 \%$ for cigars, $3.5 \%$ for smokeless tobacco, $0.9 \%$ for pipes, and $0.3 \%$ for bidis (Table 1 ). Men and 
Table 1

Prevalence and characteristics associated with current tobacco product use among adults and current polytobacco product use among adult smokers in 10 states, BRFSS 2003

\begin{tabular}{|c|c|c|c|c|c|c|c|c|c|c|c|c|}
\hline & \multicolumn{10}{|c|}{ All adults } & \multirow{2}{*}{\multicolumn{2}{|c|}{$\frac{\text { Adult smokers }}{\text { Polytobacco }}$}} \\
\hline & \multicolumn{2}{|c|}{ Cigarette } & \multicolumn{2}{|l|}{ Cigar } & \multicolumn{2}{|c|}{ Smokeless tobacco } & \multicolumn{2}{|c|}{ Pipe } & \multicolumn{2}{|c|}{ Bidi } & & \\
\hline & $\%$ & $\mathrm{OR}^{\mathrm{a}}, \mathrm{CI}(95 \%)$ & $\%$ & $\mathrm{OR}^{\mathrm{a}}, \mathrm{CI}(95 \%)$ & $\%$ & $\mathrm{OR}^{\mathrm{a}}, \mathrm{CI}(95 \%)$ & $\%$ & $\mathrm{OR}^{\mathrm{a}}, \mathrm{CI}(95 \%)$ & $\%$ & $\mathrm{OR}^{\mathrm{a}}, \mathrm{CI}(95 \%)$ & $\%$ & $\mathrm{OR}^{\mathrm{b}}, \mathrm{CI}(95 \%)$ \\
\hline All & 22.4 & - & 5.7 & - & 3.5 & - & 0.9 & - & 0.3 & - & 16.3 & - \\
\hline \multicolumn{13}{|l|}{ Gender } \\
\hline Male & 25.5 & $1.4(1.3-1.5)$ & 10.4 & $9.5(7.8-11.5)$ & 6.8 & $20.9(16.3-26.7)$ & 1.8 & $28.8(10.7-77.8)$ & 0.5 & $4.4(2.1-8.9)$ & 26.0 & $9.6(7.6-12.1)$ \\
\hline Female & 19.4 & Referent & 1.2 & Referent & 0.3 & Referent & 0.1 & Referent & 0.1 & Referent & 4.4 & Referent \\
\hline \multicolumn{13}{|l|}{ Age } \\
\hline $18-29$ & 27.1 & $1.6(1.5-1.8)$ & 8.5 & $2.3(1.9-2.7)$ & 4.4 & $1.9(1.5-2.4)$ & 1.0 & $1.0(0.6-1.6)$ & 1.1 & $54.7(23.1-129.5)$ & 22.6 & $3.3(2.6-4.1)$ \\
\hline $30-44$ & 24.6 & $1.4(1.3-1.5)$ & 6.5 & $1.7(1.5-2.0)$ & 4.5 & $2.0(1.6-2.4)$ & 0.7 & $0.7(0.5-0.9)$ & 0.2 & $10.5(4.3-25.5)$ & 17.2 & $2.2(1.8-2.7)$ \\
\hline $45+$ & 18.7 & Referent & 3.9 & Referent & 2.4 & Referent & 1.0 & Referent & 0.0 & Referent & 11.4 & Referent \\
\hline \multicolumn{13}{|l|}{ Race/ethnicity } \\
\hline White & 22.9 & $1.3(1.1-1.4)$ & 6.0 & $1.4(1.1-1.8)$ & 4.1 & $2.6(1.7-4.1)$ & 1.0 & $1.7(0.8-3.8)$ & 0.1 & $0.2(0.1-0.6)$ & 16.8 & $1.6(1.1-2.2)$ \\
\hline Black & 22.7 & $1.3(1.1-1.5)$ & 4.6 & $1.0(0.7-1.5)$ & 1.4 & $0.9(0.5-1.6)$ & 0.5 & $0.8(0.3-2.0)$ & 0.9 & $1.3(0.5-3.8)$ & 13.0 & $1.1(0.7-1.8)$ \\
\hline Other & 26.2 & $1.5(1.2-1.9)$ & 6.9 & $1.6(1.1-2.4)$ & 4.2 & $2.7(1.5-4.8)$ & 1.1 & $1.7(0.7-4.4)$ & 0.7 & $1.1(0.3-4.1)$ & 19.2 & $2.1(1.3-3.5)$ \\
\hline Hispanic & 19.0 & Referent & 4.4 & Referent & 1.6 & Referent & 0.6 & Referent & 0.7 & Referent & 13.8 & Referent \\
\hline \multicolumn{13}{|l|}{ Education } \\
\hline$\leq 12$ grade & 28.4 & $1.8(1.7-2.0)$ & 5.4 & $0.9(0.8-1.0)$ & 4.0 & $1.3(1.1-1.5)$ & 0.9 & $1.0(0.7-1.4)$ & 0.4 & $1.5(0.7-3.2)$ & 16.1 & $1.8(1.5-2.2)$ \\
\hline$>12$ grade & 17.7 & Referent & 6.0 & Referent & 3.1 & Referent & 0.9 & Referent & 0.3 & Referent & 16.6 & Referent \\
\hline \multicolumn{13}{|l|}{ Income } \\
\hline$\leq \$ 19999$ & 28.6 & $2.0(1.8-2.2)$ & 4.5 & $0.6(0.5-0.7)$ & 3.0 & $0.8(0.6-1.1)$ & 0.9 & $0.8(0.5-1.2)$ & 0.2 & $1.5(0.4-5.9)$ & 13.8 & $1.5(1.2-2.0)$ \\
\hline$\$ 20-49999$ & 26.4 & $1.8(1.6-1.9)$ & 5.2 & $0.7(0.6-0.8)$ & 3.8 & $1.0(0.8-1.2)$ & 0.8 & $0.7(0.5-1.0)$ & 0.5 & $3.3(0.9-11.9)$ & 15.8 & $1.5(1.2-1.9)$ \\
\hline$\geq \$ 50000$ & 16.8 & Referent & 7.5 & Referent & 3.7 & Referent & 1.2 & Referent & 0.1 & Referent & 18.1 & Referent \\
\hline \multicolumn{13}{|l|}{ Alcohol use } \\
\hline More-than-moderate use & 51.9 & $4.2(3.6-4.8)$ & 13.2 & $2.7(2.1-3.4)$ & 8.5 & $2.8(2.1-3.8)$ & 2.6 & $3.2(1.7-6.0)$ & 1.3 & $5.1(1.8-14.4)$ & 22.2 & $7.0(5.2-9.4)$ \\
\hline Moderate use or less & 20.5 & Referent & 5.3 & Referent & 3.2 & Referent & 0.8 & Referent & 0.3 & Referent & 15.6 & Referent \\
\hline \multicolumn{13}{|l|}{ Smoking status } \\
\hline Current & - & - & 12.3 & $4.3(3.7-5.0)$ & 4.0 & $1.4(1.1-1.7)$ & 2.0 & $4.4(3.1-6.5)$ & 0.9 & $5.3(2.2-12.8)$ & - & - \\
\hline Former & - & - & 5.2 & $1.7(1.4-2.0)$ & 4.2 & $1.5(1.2-1.8)$ & 0.9 & $2.1(1.4-3.1)$ & 0.1 & $0.7(0.2-2.5)$ & - & - \\
\hline Non smoker & - & - & 3.2 & Referent & 2.9 & Referent & 0.5 & Referent & 0.2 & Referent & - & - \\
\hline
\end{tabular}

BRFSS: Behavioral Risk Factor Surveillance System; OR: odds ratio; CI: confidence interval.

${ }^{a}$ Cigarette, cigar, smokeless tobacco, pipe, and bidi use as compared to respective nonuse of product (i.e.: cigarette use compared to non-cigarette use).

${ }^{b}$ Polytobacco use as compared to nonuse of any tobacco product. 
younger adults were significantly more likely to use all tobacco products (except pipes among younger adults) (Table 1). Prevalence of cigarette and smokeless tobacco use was also higher among those with less educational attainment, and cigarette use was higher in households with less income (Table 1). Finally, use of every tobacco product was significantly associated with more-than-moderate alcohol use, and current cigarette smokers were more likely than nonsmokers to use cigars, smokeless tobacco, pipes, and bidis (Table 1).

\subsection{Polytobacco use}

Among all adults, the prevalence of polytobacco use was 3.4\% (data not shown). Among men who smoked cigarettes, $26.0 \%$ were polytobacco users, compared with only $4.4 \%$ of women cigarette smokers (Table 1). In stratified analyses, polytobacco use was more common among men, younger adults, whites, races/ethnicities other than white, black, or Hispanic, people with lower levels of educational attainment and income, and more-than-moderate alcohol users (greater alcohol use) (Table 1). Multivariate analyses demonstrated that polytobacco use among men was most strongly associated with age 18-29 years; race/ ethnicity other than white, black, or Hispanic; $\leq 12$ th grade education, household income $\leq \$ 19999$, and greater alcohol use (Table 2).

Table 2

Characteristics associated with current cigarette only use, current polytobacco product use among adult men in 10 states, BRFSS 2003

\begin{tabular}{|c|c|c|c|c|}
\hline & \multicolumn{2}{|c|}{ Cigarettes only } & \multicolumn{2}{|c|}{ Polytobacco use } \\
\hline & $\mathrm{OR}^{\mathrm{a}}$ & CI $(95 \%)$ & $\mathrm{OR}^{\mathrm{a}}$ & CI $(95 \%)$ \\
\hline \multicolumn{5}{|l|}{ Age } \\
\hline $18-29$ & 1.2 & $(1.0-1.5)$ & 3.1 & $(2.3-4.1)$ \\
\hline $30-44$ & 1.4 & $(1.2-1.6)$ & 2.7 & $(2.1-3.5)$ \\
\hline $45+$ & 1.0 & Referent & 1.0 & Referent \\
\hline \multicolumn{5}{|l|}{ Race/ethnicity } \\
\hline White & 1.5 & $(1.2-1.9)$ & 3.6 & $(2.2-5.6)$ \\
\hline Black & 1.4 & $(1.0-1.8)$ & 2.2 & $(1.2-3.9)$ \\
\hline Other & 1.8 & $(1.2-2.5)$ & 3.7 & $(1.9-7.1)$ \\
\hline Hispanic & 1.0 & Referent & 1.0 & Referent \\
\hline \multicolumn{5}{|l|}{ Education } \\
\hline$\leq 12$ grade & 1.9 & $(1.6-2.1)$ & 2.2 & $(1.7-2.8)$ \\
\hline$>12$ grade & 1.0 & Referent & 1.0 & Referent \\
\hline \multicolumn{5}{|l|}{ Income } \\
\hline$\leq \$ 19999$ & 2.0 & $(1.6-2.5)$ & 1.7 & $(1.2-2.5)$ \\
\hline$\$ 20-49999$ & 1.8 & $(1.5-2.0)$ & 1.4 & $(1.1-1.9)$ \\
\hline$\geq \$ 50000$ & 1.0 & Referent & 1.0 & Referent \\
\hline \multicolumn{5}{|l|}{ Alcohol use } \\
\hline More-than-moderate use & 4.1 & $(3.2-5.3)$ & 5.6 & $(3.8-8.3)$ \\
\hline Moderate use or less & 1.0 & Referent & 1.0 & Referent \\
\hline
\end{tabular}

BRFSS: Behavioral Risk Factor Surveillance System; OR: odds ratio; CI: confidence interval.

${ }^{a}$ Cigarettes only, Polytobacco use as compared to nonuse of any tobacco product. 


\section{Discussion}

Among men who smoked cigarettes, one out of four used at least one other tobacco product. The high prevalence of current polytobacco use among male cigarette smokers should be a focus for at least two reasons. First, most tobacco control interventions are primarily designed to address cigarette smoking and do not address combined use of additional tobacco products (Task Force on Community Preventive Services, 2001). Second, due to legislative, environmental, and marketing factors, the use of other noncigarette tobacco products (i.e. smokeless tobacco) could increase. Possible reasons why this could occur include higher excise taxes on cigarettes, the increasing number of smoke-free policies being instituted in local communities and at the state level, and industry marketing and advertising for other tobacco products (Delnevo, Hrywna, Foulds, \& Steinberg, 2004; Henningfield, Rose, \& Giovino, 2002; Ohsfeldt, Boyle, \& Capilouto, 1997). For example, smokeless tobacco company advertisements have encouraged the use of smokeless tobacco in situations when people cannot smoke cigarettes (Henningfield et al., 2002). A recent study found cigarette smokers with a home ban on smoking were more likely to use smokeless tobacco to maintain their nicotine addiction (Mumford et al., 2005). The industry also proposes smokeless tobacco as a healthier alternative to smoking (Hatsukami, Lemmonds, \& Tomar, 2004), this is important to monitor because some researchers have found that using smokeless tobacco may actually lead to initiation of smoking (Haddock et al., 2001; Tomar, 2002).

In these 10 states, the prevalence of use for each of the specific tobacco products was generally similar to national estimates (2000 National Health Interview Survey [NHIS], public use data file). Polytobacco use was high among male cigarette smokers, but low among all adults. Of note is that population-based estimates in this study and elsewhere confirm that bidi and pipe use is rare among adults (Nelson et al., 1996; Tomar, 2003; 2000 NHIS, public use data file). Men, younger adults, more-than-moderate alcohol consumers, and current cigarette smokers were more likely to use non-cigarette tobacco products. These results are consistent with the literature that has found the use of non-cigarette tobacco products associated with men (Delnevo, Pevzner et al., 2004; Gilpin \& Pierce, 2001; Rigotti et al., 2000; Sanchez, 2001), cigarette use (Delnevo, Pevzner et al., 2004; Gilpin \& Pierce, 2001; Rigotti et al., 2000; Sanchez, 2001), and younger age (Tomar, 2002; Delnevo, Pevzner et al., 2004; Sanchez, 2001). We found younger adults were more likely to use most tobacco products. High school adolescents have reported high use of cigarettes, cigars, and smokeless tobacco in national surveys (CDC, 2004b); use may continue into young adulthood (Rigotti et al., 2000).

Polytobacco product use among men was associated with younger age; all races/ethnicities except Hispanic; less educational attainment, less household income, and greater alcohol use. Our findings are similar to prior studies examining demographic and alcohol use characteristics among adults who use cigarettes and smokeless tobacco (Lando et al., 1999; Mumford et al., 2005; Wetter et al., 2002).

It is not clear from our study why individuals used multiple tobacco products and alcohol. Some clues may be found in the literature, which cites risk-taking, sensation-seeking, and other psychosocial issues as possible reasons young adults use tobacco products and alcohol. Young adults who engage in risky behaviors such as using marijuana and having many sexual partners are more likely to use multiple tobacco products and alcohol (Rigotti et al., 2000). Multiple drug use creates an enhanced effect for users, and allows for substitution of one product for another when a particular substance isn't available (Griffith, Pederson, \& Kuiper, submitted for publication). Young adults may also be more likely to use tobacco and alcohol as a part of a college lifestyle where social life may be valued more highly than other components of college (i.e., athletic participation, educational achievement, or religion) (Rigotti et al., 2000). 
These results are subject to limitations. Data were collected from the 10 states that chose to include the tobacco product module on their surveys and may not be generalizable to other states. Estimates are also based on self-reports and not validated by biochemical markers, which could underestimate actual use. However, self-reported data on cigarette smoking and smokeless tobacco have been found to be valid in other surveys (Caraballo, Giovino, \& Pechacek, 2004; Caraballo, Giovino, Pechacek, \& Mowery, 2001; Holiday, McLarty, Yanigihara, Riley, \& Shepherd, 1995). Finally, other tobacco product use questions and definitions differ slightly between the BRFSS and the NHIS, limiting the ability to make true comparisons (i.e. the NHIS contains an additional question for each specific product on having used or smoked the product at least 20-50 times, which is used to define current use).

All tobacco products are associated with adverse health consequences and no tobacco product use is safe (American Society of Clinical Oncology, 2003; Deckers, Farley, \& Heath, 2006; NCI, 1998, 1992). Along with these health concerns, several questions about polytobacco use remain. Are polytobacco users less likely than single-product users to quit smoking? Are they more nicotine-dependent? How or why do they become polytobacco users? Answers to these questions are needed for the design of effective interventions which address polytobacco use. Given the fact that younger men tend to be polytobacco users, programs targeting this population, e.g., in worksites or on college campuses, may be needed. Some strategies that might be effective for reducing use of all tobacco products include raising rates of taxes on all tobacco products (Campaign for Tobacco-Free Kids, 2003; Delnevo, Hrywna et al., 2004; Ohsfeldt \& Boyle, 1994; Ohsfeldt et al., 1997; USDHHS, 2000), reducing access to tobacco products by minors (CDC, 1999), targeting tobacco control media and ad campaigns to users of other tobacco products such as smokeless tobacco (Task Force on Community Preventive Services, 2001), and including polytobacco use in telephone quit line counseling (CDC, 2004a).

\section{References}

American Society of Clinical Oncology. (2003). American Society of Clinical Oncology policy statement update: Tobacco control-reducing cancer incidence and saving lives. Journal of Clinical Oncology, 21, 2777-2787.

Campaign for Tobacco-Free Kids. (2003). State excise tax rates for non-cigarette tobacco products. Retrieved December 2005 from http://tobaccofreekids.org/research/factsheets/pdf/0169.pdf

Caraballo, R. S., Giovino, G. A., \& Pechacek, T. F. (2004). Self-reported cigarette smoking vs. serum cotinine among U.S. adolescents. Nicotine \& Tobacco Research, 6, 19-25.

Caraballo, R. S., Giovino, G. A., Pechacek, T. F., \& Mowery, P. D. (2001). Factors associated with discrepancies between selfreports on cigarette smoking and measured serum cotinine levels among persons aged 17 years or older. American Journal of Epidemiology, 153, 807-814.

Centers for Disease Control and Prevention. (1999). Best practices for comprehensive tobacco control programs. Atlanta, GA: U.S. Department of Health and Human Services.

Centers for Disease Control and Prevention. (2003). Cigarette smoking-attributable morbidity_United States, 2000. MMWR, 52 (35), 842-844.

Centers for Disease Control and Prevention. (2004). Telephone quitlines: A resource for development, implementation, and evaluation. Atlanta, GA: U.S. Department of Health and Human Services.

Centers for Disease Control and Prevention. (2004). Tobacco use, access, and exposure to tobacco in media among middle and high school students-United States. MMWR, 54, 297-301.

Centers for Disease Control and Prevention. (2005). Annual smoking-attributable mortality, years of potential life lost, and productivity losses-United States, 1997-2001. MMWR, 54, 625-628.

Centers for Disease Control and Prevention. (2005). About the BRFSS. Retrieved December 2005 from http://www.cdc.gov/ brfss/about.htm

Centers for Disease Control and Prevention. (2005). State-specific prevalence of cigarette smoking and quitting among adultsUnited States, 2004. MMWR, 54, 1124-1127. 
Deckers, S. K., Farley, J., \& Heath, J. (2006). Tobacco and its trendy alternatives: Implications for pediatric nurses. Critical Care Nursing Clinics of North America, 18, 95-104.

Delnevo, C. D., Hrywna, M., Foulds, J., \& Steinberg, M. B. (2004). Cigar use before and after a cigarette excise tax increase in New Jersey. Addictive Behaviors, 29, 1799-1807.

Delnevo, C. D., Pevzner, E. S., Hrywna, M., \& Lewis, M. J. (2004). Bidi cigarette use among young adults in 15 states. Preventive Medicine, 39, 207-211.

Gilpin, E. A., \& Pierce, J. P. (2001). Patterns of cigar use in California in 1999. American Journal of Preventive Medicine, 21, 325-328.

Gilpin, E. A., \& Pierce, J. P. (2003). Concurrent use of tobacco products by California adolescents. Preventive Medicine, 36, 575-584

Griffith, R.P., Pederson, L.L., \& Kuiper, N. (submitted for publication). Between adolescence and adulthood: Young adult cigarette smokers from college class to working class.

Haddock, C. K., Vander Weg, M., DeBon, M., Klesges, R. C., Talcott, G. W., Lando, H., et al. (2001). Evidence that smokeless tobacco use is a gateway for smoking initiation in young adult males. Preventive Medicine, 32, $262-267$.

Hatsukami, D. K., Lemmonds, C., \& Tomar, S. L. (2004). Smokeless tobacco use: Harm reduction or induction approach? Preventive Medicine, 38, 309-317.

Henley, S. J., Thun, M. J., Chao, A., \& Calle, E. E. (2004). Association between exclusive pipe smoking and mortality from cancer and other diseases. Journal of the National Cancer Institute, 96, 853-861.

Henningfield, J. E., Rose, C. A., \& Giovino, G. A. (2002). Brave new world of tobacco disease prevention: Promoting dual tobacco-product use? American Journal of Preventive Medicine, 23, 226-228.

Holiday, D. B., McLarty, J. W., Yanigihara, R. H., Riley, L., \& Shepherd, S. B. (1995). Two biochemical markers effectively used to separate smokeless tobacco users from smokers and nonusers. Southern Medical Journal, 88, 1107-1113.

Lando, H. A., Haddock, C. K., Klesgess, R. C., Talcott, G. W., \& Jensen, J. (1999). Smokeless tobacco use in a population of young adults. Addictive Behaviors, 24, 431-437.

Mumford, E. A., Levy, D. T., Gitchell, J. G., \& Blackman, K. O. (2005). Tobacco control policies and the concurrent use of smokeless tobacco and cigarettes among men, 1992-2002. Nicotine \& Tobacco Research, 7, 891-900.

National Cancer Institute. (1992). Smokeless tobacco or health: An international perspective. Monograph, Vol. 2. Bethesda, MD: United States Department of Health and Human Services, National Institutes of Health, National Cancer Institute.

National Cancer Institute. (1998). Cigars. Health effects and trends. Monograph, Vol. 9. Bethesda, MD: United States Department of Health and Human Services, National Institutes of Health, National Cancer Institute.

Nelson, D. E., Davis, R. M., Chrismon, J. H., \& Giovino, G. A. (1996). Pipe smoking in the United States, 1965-1991: Prevalence and attributable mortality. Preventive Medicine, 25, 91-99.

Ohsfeldt, R. L., \& Boyle, R. G. (1994). Tobacco excise taxes and rates of smokeless tobacco use in the US: An exploratory ecological analysis. Tobacco Control, 3, 316-323.

Ohsfeldt, R. L., Boyle, R. G., \& Capilouto, E. (1997). Effects of tobacco excise taxes on the use of smokeless tobacco products in the U.S.A.. Health Economics, 6, 525-531.

Rigotti, N. A., Lee, J. E., \& Wechsler, H. (2000). US college students' use of tobacco products: Results of a national survey. Journal of the American Medical Association, 284, 699-705.

Sanchez, R. P. (2001). Cigar and pipe smoking in the US military: Prevalence, trends, and correlates. Military Medicine, 166, 903-908

Task Force on Community Preventive Services (2001). Recommendations regarding interventions to reduce tobacco use and exposure to environmental tobacco smoke. American Journal of Preventive Medicine, 20, 10-15.

Tomar, S. L. (2002). Snuff use and smoking in US men: Implications for harm reduction. American Journal of Preventive Medicine, 23, 143-149.

Tomar, S. L. (2003). Trends and patterns of tobacco use in the United States. American Journal of the Medical Sciences, 326, 248-254.

U.S. Department of Agriculture. Briefing Room. Tobacco: Data Tables. Expenditures for tobacco products and disposable personal income, 1989-2005 (Table 21). Washington, DC: U.S. Department of Agriculture, Economic Research Service. Retrieved April 2006 from http://www.ers.usda.gov/briefing/Tobacco/Data/table21.pdf

U.S. Department of Health and Human Services. (2000). Reducing tobacco use: A report of the Surgeon General. Atlanta, GA: Centers for Disease Control and Prevention.

U.S. Department of Health and Human Services. (2004). The health consequences of smoking: A report of the Surgeon General. Atlanta, GA: Centers for Disease Control and Prevention. 
U.S. Department of Health and Human Services \& U.S. Department of Agriculture. (2005, January). Dietary guidelines for Americans, 2005 (6th edition). Washington, DC: U.S. Government Printing Office. Retrieved February 2007 from http://www.healthierus.gov/dietaryguidelines

Wetter, D. W., McClure, J. B., de Moor, C., Cofta-Gunn, L., Cummings, S., Cinciripini, P. M., \& Gritz, E. R. (2002). Concomitant use of cigarettes and smokeless tobacco: Prevalence, correlates, and predictors of tobacco cessation. Preventive Medicine, 34, 638-648.

Wu, W., Song, S., Ashley, D. L., \& Watson, C. H. (2004). Assessment of tobacco-specific nitrosamines in the tobacco and mainstream smoke of bidi cigarettes. Carcinogenesis, 25, 283-287. 